TITLE:

\title{
Predation risk increases dispersal distance in prey.
}

$\operatorname{AUTHOR}(S)$ :

Otsuki, Hatsune; Yano, Shuichi

CITATION:

Otsuki, Hatsune ...[et al]. Predation risk increases dispersal distance in prey.. Naturwissenschaften 2014, 101(6): 513-516

ISSUE DATE:

2014-06

URL:

http://hdl.handle.net/2433/199893

\section{RIGHT:}

The final publication is available at Springer via http://dx.doi.org/10.1007/s00114-0141181-3.; この論文は出版社版でありません。引用の際には出版社版をご確認ご利用くだ

さい。; This is not the published version. Please cite only the published version. 


\section{$1 \quad$ Predation risk increases dispersal distance in prey}

3 Hatsune Otsuki ${ }^{a^{*}}$, Shuichi Yano ${ }^{\text {a }}$

$4{ }^{a}$ Laboratory of Ecological Information, Graduate School of Agriculture, Kyoto University, Kyoto

5 606-8502, Japan

$6 \quad *$ Corresponding author: ootsuki.hatsune.44e@st.kyoto-u.ac.jp

$7 \quad$ Tel \& fax: $+81-75-753-6144$ 


\section{Abstract}

10 Understanding the ecological factors that affect dispersal distances allows us to predict the

11 consequences of dispersal. Although predator avoidance is an important cause of prey dispersal, its

12 effects on dispersal distance have not been investigated. We used simple experimental setups to test

13 dispersal distances of the ambulatory dispersing spider mite (Tetranychus kanzawai) in the presence

14 or absence of a predator (Neoseiulus womersleyi). In the absence of predators, most spider mites settled in adjacent patches, whereas the majority of those dispersing in the presence of predators passed through adjacent patches and settled in distant ones. This is the first study to experimentally demonstrate that predators induce greater dispersal distance in prey.

\section{Keywords}

20 Conditional dispersal, dispersal distance, antipredator behavior, settlement decision, spider mite

\section{Introduction}

24 Dispersal ecology aims to elucidate how ecological factors affect the dispersal processes of

25 organisms. Although dispersal consists of three distinct phases-departure, transfer and settlement

26 (Clobert et al. 2009) — most theoretical and empirical studies have focussed only on departure 
27 (Bowler and Benton 2005). However, while departure rate is informative, dispersal distances

28 post-departure are necessary to predict the full consequences of dispersal (Travis et al. 2013). The

29 ability of individuals to reach and settle into a suitable habitat patch can determine the fate of their

30 populations, and thus the species (Kokko and Lopez-Sepulcre 2006; Travis et al. 2013), which is

31 especially true when faced with increasing habitat fragmentation and climate change. Therefore, understanding the ecological factors influencing dispersal distance is of crucial importance in changing environments.

Actively dispersing organisms depart their natal patches, making decisions based on

dispersal costs and benefits (Bonte et al. 2012). Once individuals have reached a potential patch, they must decide whether to settle or to continue searching for more suitable patches based on the costs and benefits of further dispersal (Bonte et al. 2012). The primary benefit of dispersal is leaving a patch with relatively lower fitness expectations due to resource deterioration and/or kin competition (Hamilton and May 1977). An increasing number of theoretical studies have investigated the

40 influences of these factors on the evolution of dispersal distance (e.g. Rousset and Gandon 2002;

41 Poethke et al. 2011). Furthermore, empirical studies have demonstrated that density and/or kin competition induces plasticity for dispersal distance in actively dispersing organisms such as small mammals (Ims and Andreassen 2005) and herbivorous mites (Bitume et al. 2013). 
1990), predators may affect not only the probability of departure (e.g. McCauley and Rowe 2010),

but also patch settlement decisions and dispersal distances of prey. However, to our knowledge, only

a few studies have considered the effects of predators on prey dispersal distances (Tamaki et al.

1970; Weisser et al. 1999; Meng et al. 2012). Tamaki et al. (1970) compared spatial distributions of

apterous aphid populations in the presence or absence of parasitoids, and inferred that those aphids

dispersed a greater distance if they encountered parasitoids. Similarly, Weisser et al. (1999)

demonstrated that predators induced winged offspring in aphids, suggesting predator-induced

long-distance dispersal. However, Meng et al. (2012) did not detect increased dispersal distances in

adult whiteflies in the presence of predators. The scarcity of studies examining dispersal distances of

prey organisms may be due largely to the difficulty in tracking flying organisms that disperse great

distances.

To facilitate observation of the prey dispersal process, we used the ambulatory dispersing

spider mite Tetranychus kanzawai Kishida (Acari: Tetranychidae) and its native predator Neoseiulus

womersleyi Schicha (Acari: Phytoseiidae). Spider mites in the genus Tetranychus are major

60 agricultural pests living in protective webs on leaf surfaces (Saito 1983). In response to plant

61 deterioration, mated females disperse, mainly by walking to a new plant (Brandenburg and Kennedy

62 1982). However, specialist predatory mites, such as $N$. womersleyi, that can penetrate these webs also

63 promote the dispersal of spider mites (e.g. Bernstein 1984; Grostal and Dicke 1999). Since such

64 predators are used as biological control agents against spider mites (Sabelis and Bakker 1992), 


\section{$70 \quad$ Material and methods \\ Material and methods}

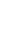

understanding their effects on the prey dispersal process is also of economic importance.

Here, we tested the hypothesis that spider mites perceiving a predation risk disperse farther than those dispersing in response to resource deterioration. This is the first experimental demonstration of predators increasing dispersal distances in prey organisms.

2 We collected T. kanzawai from narrow-leaved vetch (Vicia sativa subsp. nigra L.; Fabaceae) in Kyoto, Japan. Individuals were maintained on kidney bean (Phaseolus vulgaris L.; hereafter "bean") leaf discs pressed onto water-saturated cotton in Petri dishes (90 $\mathrm{mm}$ in diameter, $14 \mathrm{~mm}$ in depth). We collected $N$. womersleyi individuals from Rosa centifolia L. (Rosaceae) in Nara, Japan. Individuals were reared on bean leaf discs heavily infested with T. urticae as prey. All rearing and experiments were conducted under $25^{\circ} \mathrm{C}, 50 \%$ relative humidity and an L16:D8 photoperiod.

Our experimental setup contained three connected leaf patches (Fig. 1a). We introduced a mated 2-day-old female spider mite onto a $10 \times 10 \mathrm{~mm}$ bean leaf square (initial patch) and allowed her to build webs for $24 \mathrm{~h}$. We then introduced an adult female predatory mite onto the initial patch (predator present), while setups without a predator served as controls (predator absent). Since we intended to examine spider mite dispersal in response to a predator staying in the initial patch, predators were fed only water for the previous $48 \mathrm{~h}$, as they remain in the initial patch containing 
84 abundant spider mite eggs longer than predators with previous access to food (SY, unpublished data).

85 After allowing the predators to acclimate for $30 \mathrm{~min}$, we connected the initial patch to two other consecutive leaf squares (second and third patches) with $10 \times 30 \mathrm{~mm}$ Parafilm bridges. This setup was surrounded by water-saturated cotton to prevent mites from escaping.

We recorded the location and state of spider mites every $24 \mathrm{~h}$ until each had dispersed to

either of the two consecutive patches. We identified which patch each spider mite first settled; we

considered a patch as settled if it contained webs, injury scars, eggs and faeces of spider mites,

regardless of the mites' presence. We excluded the data when predatory mites intruded into

consecutive patches.

To confirm that female spider mites were not attracted to bean leaves at a distance of $30 \mathrm{~mm}$

94 (as examined above), we connected a leaf and a Parafilm square $(10 \times 10 \mathrm{~mm}$ each) with a T-shaped

95 Parafilm pathway (Fig. 1b) and introduced a female spider mite $(N=60)$ at the bottom of the pathway.

96 The number of females that moved in each direction from the T-junction did not significantly differ

97 from equality (leaf:control, 28:32; binomial test, $P=0.70$ ) (Fig. 1b). Therefore, dispersing spider

98 mites were considered to have abandoned the previous patch, as opposed to having been attracted to

99 adjacent patches, and that dispersal between patches connected with nonfood substrates could 100 simulate ambulatory mite dispersal between remote patches. 
104 The mean time (day \pm SE) before spider mites began dispersing was significantly shorter in the 105 presence of predators $(1.3 \pm 0.11)$ than in their absence $(5.8 \pm 0.30$; Mann-Whitney $U$-test, $P<0.0001)$, 106 suggesting that spider mite dispersal is dependent on predators. If predators are absent, dispersal is 107 seemingly triggered by resource deterioration, but if predators are present, they become important 108 dispersal motivators. This was consistent with results of previous studies reporting higher spider mite 109 departure rates in the presence of specialist predatory mites (e.g. Bernstein 1984; Grostal and Dicke 110 1999). Furthermore, we showed that most spider mites dispersing in the absence of predators settled 111 in adjacent (second) patches, whereas the majority of those dispersing in the presence of predators settled in distant (third) patches (Fisher's exact test, $P=0.0020$ ) (Fig. 2). Thus, we experimentally

113 demonstrated that predators increase prey departure rate and dispersal distance.

\section{Discussion}

117 In general, dispersing organisms adjust their behaviours based on the costs and benefits of dispersal

118 (Bonte et al. 2012). That is, an individual that has reached a potential patch has the option to remain 119 or to continue dispersing. Our results, showing that most prey individuals settled in adjacent patches 120 in the absence of predators, support published theoretical research (Poethke et al. 2011). These 121 authors predicted that dispersing individuals should settle in adjacent patches unless the cost of 
122 between-patch dispersal is extremely low because the costs of resource competition should

123 sufficiently decrease after one dispersal step. Although dispersal costs were not simulated in our

124 experiments, the average costs of between-patch dispersal that spider mites should incur in the wild

125 may be considerable because their webs serve as refuges from numerous predators (Yano 2012) and

126 spider mites in the open are extremely vulnerable. Our results imply that ignoring the first

127 encountered patch is disadvantageous for spider mites when the predation risk by specialist predatory

128 mites is low. Conversely, prey individuals dispersing greater distances in response to predators may

129 benefit from escaping predators, not only because they move farther away from the invaded patch,

130 but also because the probability of being tracked by predators substantially decreases with every

131 between-patch dispersal event in the wild, where multiple dispersal directions are available. We

132 showed that the majority of spider mites dispersing in the presence of specialist predatory mites

passed through adjacent patches without settling, which implies that the benefits of greater dispersal

134 distances under predation risk may outweigh the average costs of dispersal.

In contrast to departure rate, the ecological factors that influence dispersal distance are less

understood. This is the first empirical study to demonstrate that predators induce greater dispersal

137 distance in individual prey. Thus, both the departure rate (Bowler and Benton 2005) and dispersal

138 distance appear to be affected by predation risk. Fronhofer et al. (2014) empirically and theoretically

139 demonstrated that spatially correlated local extinctions select for long-distance dispersal. Contrary to

140 unpredictable extinction events such as disease outbreak (Muller-Landau et al. 2003) and habitat 
141 fragmentation (Kallimanis et al. 2006), extinctions of local spider mite populations by specialist

142 predators should be predictable because individuals can perceive intruding predators (e.g. Bernstein

143 1984; Grostal and Dicke 1999); therefore, conditional dispersal strategies in response to the presence

144 of predators, as observed in our study, would be more advantageous than fixed strategies insensitive

145 to predation risk.

$146 \quad$ Our results imply that the distribution of dispersal distances (dispersal kernel) measured in

147 the absence of predators (Bitume et al. 2013; Fronhofer et al. 2014) should be significantly different

148 when predators are present. Further empirical studies are required to understand how greater

149 dispersal distances in response to predation risk contribute to the stability of prey populations and

150 how this in turn influences the effectiveness of predators in suppressing prey populations. Addressing

151 these questions would allow us to predict invasion rates of a prey species expanding its range (Kokko

152 and Lopez-Sepulcre 2006), and in particular, insights into these issues regarding mite predator-prey

153 interactions could contribute to the successful biological control of spider mites.

\section{Acknowledgments}

157 We thank three anonymous reviewers for thoughtful suggestions, and members of the Laboratory of

158 Ecological Information for valuable suggestions and encouragement. 


\section{References}

162 Bernstein C (1984) Prey and predator emigration responses in the acarine system Tetranychus urticae-Phytoseiulus persimilis. Oecologia 61:134-142. doi: 10.1007/BF00379099

Bitume EV, Bonte D, Ronce O, Bach F, Flaven E, Olivieri I, Nieberding CM (2013) Density and genetic relatedness increase dispersal distance in a subsocial organism. Ecol Lett 16:430-437.

Bonte D, Van Dyck H, Bullock JM et al (2012) Costs of dispersal. Biol Rev 87:290-312. doi: 10.1111/j.1469-185X.2011.00201.x doi:10.1111/j.1570-7458.1982.tb03217.x

Clobert J, Le Galliard JF, Cote J, Meylan S, Massot M (2009) Informed dispersal, heterogeneity in animal dispersal syndromes and the dynamics of spatially structured populations. Ecol Lett 12:197-209. doi: 10.1111/j.1461-0248.2008.01267.x

178 Fronhofer EA, Stelz JM, Lutz E, Poethke HJ, Bonte D (2014) Spatially correlated extinctions select 
for less emigration but larger dispersal distances in the spider mite Tetranychus urticae. Evolution (in press) doi: 10.1111/evo.12339

Grostal P, Dicke M (1999) Direct and indirect cues of predation risk influence behavior and reproduction of prey: a case for acarine interactions. Behav Ecol 10:422-427. doi: 10.1093/beheco/10.4.422

Hamilton WD, May RM (1977) Dispersal in stable habitats. Nature 269:578-581

Ims RA, Andreassen HP (2005) Density-dependent dispersal and spatial population dynamics. Proc R Soc B Biol Sci 272:913-918. doi: 10.1098/rspb.2004.3025 changing world. Science 313:789-791. doi: 10.1126/science.1128566

Lima SL, Dill LM (1990) Behavioral decisions made under the risk of predation: a review and prospectus. Can J Zool 68:619-640. doi: 10.1139/z90-092

McCauley SJ, Rowe L (2010) Notonecta exhibit threat-sensitive, predator-induced dispersal. Biol Lett 6:449-452. doi: 10.1098/rsbl.2009.1082

Meng R-X, Sabelis MW, Janssen A (2012) Limited predator-induced dispersal in whiteflies. PLoS

197 Muller-Landau HC, Levin SA, Keymer JE (2003) Theoretical perspectives on evolution of 
long-distance dispersal and the example of specialized pests. Ecology 84:1957-1967. doi:

Poethke HJ, Gros A, Hovestadt T (2011) The ability of individuals to assess population density influences the evolution of emigration propensity and dispersal distance. J Theor Biol 282:9399. doi: 10.1016/j.jtbi.2011.05.012

doi: 10.1046/j.1420-9101.2002.00430.x

Sabelis MW, Bakker FM (1992) How predatory mites cope with the web of their tetranychid prey: a distance-dependent cost of dispersal. J Evol Biol 15:515-523. functional view on dorsal chaetotaxy in the Phytoseiidae. Exp Appl Acarol 13:203-225. doi: Aphidius smithi (Hymenoptera: Aphidiidae). Ann Entomol Soc Am 63:973-980 10.1007/BF01193804

Saito Y (1983) The concept of "life types" in Tetranychinae. An attempt to classify the spinning behaviour of Tetranychinae. Acarologia 24:377-391

Tamaki G, Halfhill JE, Hathaway DO (1970) Dispersal and reduction of colonies of pea aphids by

Travis JMJ, Delgado M, Bocedi G et al (2013) Dispersal and species' responses to climate change. 
217 Yano S (2012) Cooperative web sharing against predators promotes group living in spider mites.

Behav Ecol Sociobiol 66:845-853. doi: 10.1007/s00265-012-1332-5 


\section{Figure captions}

220

221 Fig. 1 a An experimental setup to investigate whether spider mites settle in adjacent (second) patches

222 or continue to distant (third) patches in the presence or absence of predators. $\mathbf{b}$ An experiment to 223 confirm that female spider mites are not attracted to bean leaves at a distance of $30 \mathrm{~mm}$.

225 Fig. 2 The proportion of spider mites that settled in adjacent (second) or distant (third) patches.

226 Significantly more spider mites that encountered predatory mites settled in distant patches than those 227 dispersing in response to resource deterioration (Fisher's exact test). Replicate numbers are shown in 228 bars.

231 The English in this document has been checked by at least two professional editors, both native 232 speakers of English. For a certificate, please see: 
(a)
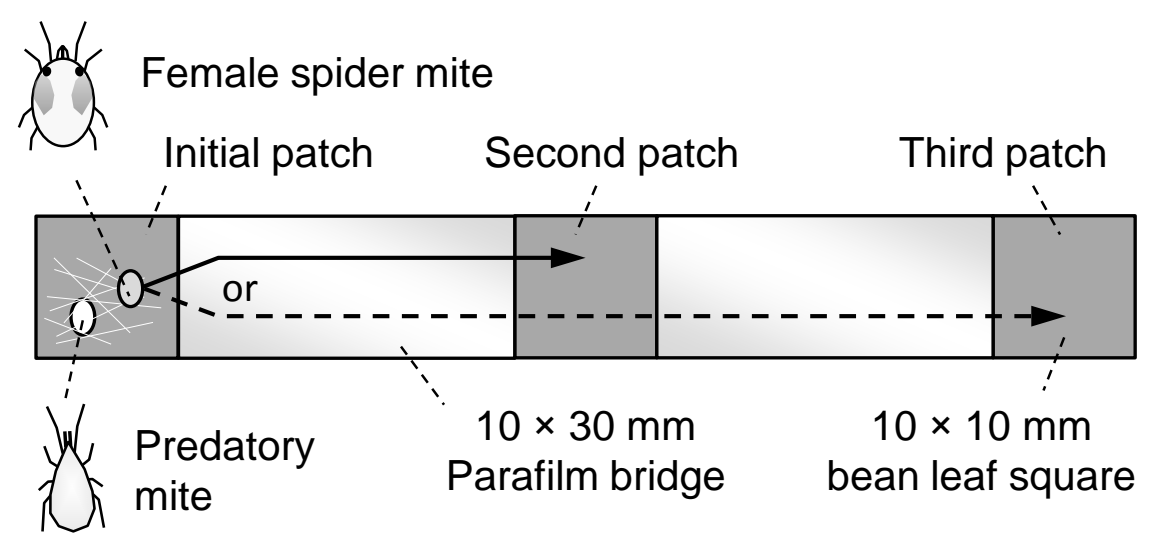

(b)

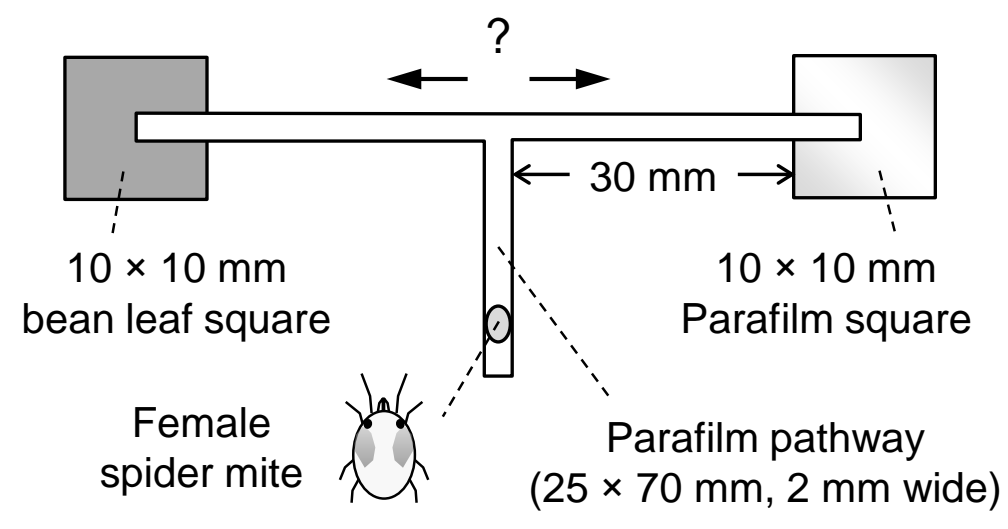

Fig. 1 


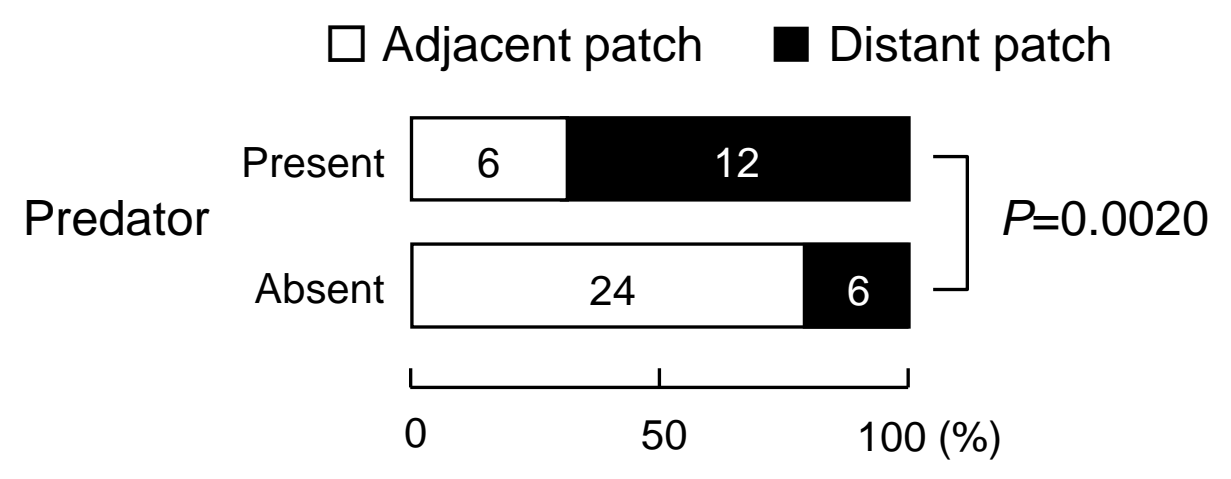

Fig. 2 